\title{
How to Select a Requirements Management Tool: Initial Steps
}

\author{
Orlena Gotel $^{1}$ and Patrick Mäder ${ }^{2}$ \\ ${ }^{1}$ Department of Computer Science \\ Pace University, New York, USA \\ ogotel apace. edu \\ ${ }^{2}$ Department of Software Systems \\ Ilmenau Technical University, Germany \\ patrick.maederetu-ilmenau.de
}

\begin{abstract}
This mini-tutorial will provide high-level guidance on designing a requirements management solution and selecting a requirements management tool. The guidance will focus on first understanding the context, stakeholders and tasks, so on articulating the problems that need to be addressed and the constraints that shape viable options. The guidance will also attend to the equally critical issue of managing the high expectations that are typically associated with requirements management tool adoption and use. Through examining the minimum and desirable requirements, based upon the type and size of project, the question of whether a requirements management tool is needed at all can also be considered.
\end{abstract}

Keywords: Expectation management, requirements engineering, requirements management, requirements management tools, tool evaluation, tool selection.

\section{Motivation for Tutorial}

Requirements management tools form an integral part of most requirements management solutions. As a consequence, procuring a requirements management tool can be one of the most costly decisions an organization can make. If hasty decisions are made, the initial costs can be negligible in relation to the subsequent impact on the organization's software development and maintenance efforts. Any investment in a requirements management tool is thereby often a strategic investment in the future ability of an organization to do business.

Despite what appears to be an abundance of useful information for those practitioners who are faced with designing and implementing requirements management solutions (see the next section for a summary of some of this information), the question: 'which requirements management tool do you recommend?' is still one that gets posed regularly on requirements engineering mailing lists and at require- ments engineering conferences. This mini-tutorial aims to pre-empt this question at RE'09 and to summarize some of the more salient points from this extensive resource base.

For clarity, the mini-tutorial will adopt the definition of requirements management as recommended by the Software Engineering Institute:

The purpose of Requirements Management (REQM) is to manage the requirements of the project's products and product components and to identify inconsistencies between those requirements and the project's plans and work products.

[3].

Requirements management is therefore the activity concerned with the effective control of information related to system requirements and, in particular, the preservation of the integrity of that information for the life of the system and with respect to changes in the system and its environment. Tools to support the wider aspects of requirements engineering, such as the initial exploration and negotiation of stakeholder needs, will not be the primary focus.

\section{Selecting Requirements Management Tools}

A number of evaluation frameworks exist to assist practitioners in selecting requirements management tools. One of the most extensive, maintained and updated since the 1990s, is that which is available on the website of the International Council on Systems Engineering (INCOSE) [10]. It provides a list of features through which a number of leading commercial and open-source tools can be compared. While useful for a cursory assessment, tool selection based solely upon a matching of desired and reported features can lead to a somewhat misguided procurement decision, particularly if the needs assessment is driven purely by available functionality. It should also be noted that the framework has been populated by answers to standard survey questions, as completed by the tool vendors themselves, so further independent research is obviously required of practitioners for decision-making purposes. 
In addition to such comparative frameworks, a number of leading requirements engineering consultants maintain relatively up-to-date descriptions of current commercial and open-source tools for requirements management on their websites (The Atlantic Systems Guild [16] and Ian Alexander [1] providing for two popular independent resources). In the industry press, a four hundred page issue of a German magazine for IT professionals ' $i X$ ' was also recently dedicated to the topic of requirements management and the supporting tools [11] (available only in German).

Since the emergence of commercial requirements management tools in the late 1980s and early 1990s, a number of articles have been written to help practitioners with the tricky problem of tool selection. Wiegers, for instance, offers very practical advice for automating an established requirements management process and matches four popular tools of the 1990s to a set of core features [18]. Providing for more depth, Hoffman et al. present a role-oriented perspective on the required features of a requirements management tool and offer a comprehensive catalog of requirements for requirements management tools based upon this work [9]. Further, a value-based approach to tool selection has been developed at Siemens Program and Systems Engineering and this is described in Heindl et al. [7]. This approach considers the value contribution of individual tool features in order to rate a tool's support for different project types.

Most text books that focus on requirements engineering also cover support for requirements management. For example, Rupp's text includes a fourteen page questionnaire designed to assist with the evaluation and selection of requirements management tools [12], while an updated version of this text includes a chapter that focuses upon how to find the right tool for a company and project [13] (both editions available only in German). Ebert's text also includes a chapter on requirements management tools and a checklist for selecting a tool [5] (also available only in German). Meanwhile, the new text by Berenbach et al. dedicates an entire appendix to explaining how to configure and manage a requirements database to support requirements management [2]. Practitioners recognize that this is an outstanding problem worthy of attention.

In addition to describing core features, the independent technology and market research company Forrester Research, Inc. delineate those features they consider out of scope for a requirements management tool [15]. More pertinently, they challenge practitioners to consider the nature of the wider requirements problem in their organization first and foremost in order to determine whether a requirements management tool is actually needed at all. Requirements management solutions was also the topic of a Forrester Wave ${ }^{\mathrm{TM}}$ in 2008 [14]. Such publications claim to employ an objective methodology to evaluate competing vendor products so as to support customers to-be in their decision-making.

All such frameworks and practitioner guidance tend to omit the alternative option of developing a home-grown tool for requirements management. Recently, it has become increasingly common to adapt tools primarily designed for other purposes (such as defect and issue-tracking tools) or to configure general-purpose tools (such as wikis) to achieve lightweight support for requirements management [4]. This route is one that has been taken by many over the years, even as the number of available offerings has grown and the range of support and price has widened, but it is a route that also presents its challenges if not tackled in a systematic and problem-oriented manner.

A number of useful experience reports have been written by practitioners that provide for a sobering perspective on practice when it comes to requirements management tool selection and adoption. For example, Hammer and Huffman discuss the risks to a project of using a requirements management tool incorrectly and argue the need to bring various stakeholders together to define tool use before setting off [6]. Tvete alerts others to how the effort involved in evaluating requirements management tools can be somewhat underestimated when attempting to introduce an improved requirements management process into an organization [17]. Higgins et al. explain the dilemma of how it is ineffective to introduce a requirements management tool without a process, yet how it is equally difficult to implement a process without a supporting tool, so advises parallel introduction [8].

\section{Tutorial Outline and Objectives}

This mini-tutorial will attempt to address the somewhat invariable and inevitable question of 'which requirements management tool?' by providing a problem-oriented framework through which to reformulate the question and so guide decision-making. Rather than a point solution, tools form part of a wider requirements management solution that depends upon the situation, underlying process, people, levels of investment and many other factors, so the question will be examined within this broader context.

The mini-tutorial will therefore articulate the more fundamental questions that need to be asked to uncover the requirements and constraints surrounding requirements management solutions and the tool selection process. It will also provide some guidance on the prerequisite and ongoing activities that underpin the successful adoption of tools. Challenges and common pitfalls will be highlighted, along with the critical issue of expectation management. Examples will be used to illustrate concepts during the mini-tutorial, though the intention is not to single out tools or to compare and contrast actual tool offerings. Rather, the goal is to 
provide practitioners with a high-level framework and initial starting point through which to guide their own future enquiry and discovery.

\section{Audience for Tutorial}

The mini-tutorial will be targeted primarily toward those practitioners concerned with improving the effectiveness and efficiency of requirements management practice within their organization and on their projects, and those attempting to navigate the various requirements management tool offerings. It will also be of some interest to requirements management tool vendors, consultants who help organizations to configure and adapt tools to their processes, researchers studying the topic and educators exploring the use of requirements management tools in the classroom.

Acknowledgments The authors would like to thank the RE'09 Program Chair (Kevin Ryan), the Chairs of the Practitioner Track (Brian Berenbach and Erik Simmons), and Norah Power for early feedback that helped to scope this mini-tutorial.

\section{References}

[1] I. Alexander. Requirements Tools Listing. http: //easyweb. easynet.co.uk/ iany/ other/other_sites.htm.

[2] B. Berenbach, D. Paulish, J. Kazmeier, and A. Rudorfer. Software \& Systems Requirements Engineering: In Practice. McGraw-Hill, 2009.

[3] CMMI Product Team. CMMI for Development, Version 1.2. Technical Report CMU/SEI-2006-TR-008, Carnegie Mellon University Software Engineering Institute, August 2006.

[4] B. Decker, E. Ras, J. Rech, P. Jaubert, and M. Rieth. Wikibased stakeholder participation in requirements engineering. IEEE Software, 24(2):28-35, 2007.

[5] C. Ebert. Systematisches Requirements Management. Dpunkt verlag, Heidelberg, 2005.

[6] T. Hammer and L. Huffman. Automated Requirements Management - Beware HOW You Use Tools: An Experience Report. In Proceedings of the Third International Conference on Requirements Engineering (ICRE'98), pages 3440, Los Alamitos, CA, USA, 1998. IEEE Computer Society.

[7] M. Heindl, F. Reinisch, S. Biffl, and A. Egyed. Valuebased selection of requirements engineering tool support. In EUROMICRO-SEAA, pages 266-273, 2006.

[8] S. A. Higgins, M. de Laat, P. M. C. Gieles, and E. M. Geurts. Managing product requirements for medical it products. In Proceedings 10th IEEE International Requirements Engineering Conference (RE'02), pages 341-349, Los Alamitos, CA, USA, 2002. IEEE Computer Society.

[9] M. Hoffmann, N. Kuhn, M. Weber, and M. Bittner. Requirements for requirements management tools. In $R E$ '04: Proceedings of the Requirements Engineering Conference, 12th IEEE International, pages 301-308, Washington, DC, USA, 2004. IEEE Computer Society.

[10] INCOSE Tools Database Working Group (TDWG). INCOSE Requirements Management Tools Survey. www. incose.org/ProductsPubs/products / toolsdatabase.aspx.

[11] A. Kress, R. Stevenson, R. Wiebel, C. Hood, and G. Versteegen. Requirements Engineering Methoden und Techniken, Einführungsszenarien und Werkzeuge im Vergleich. iX Studie Anforderungsmanagement. Heise Verlag, 2 edition, 2007. ISBN 9783936931198.

[12] C. Rupp. Requirements-Engineering und -Management. Hanser Fachbuch-Verlag, Leipzig, Germany, 2nd edition, 2002.

[13] C. Rupp. Requirements-Engineering und -Management: Professionelle, iterative Anforderungsanalyse für die Praxis. Carl Hanser Verlag, Leipzig, Germany, 4th edition, 2007.

[14] C. Schwaber and M. Gerush. The Forrester Wave ${ }^{\mathrm{TM}}$ : Requirements Management Q2 2008. Forrester Research, Inc., May 302008.

[15] C. Schwaber and P. Sterpe. Selecting The Right Requirements Management Tool - Or Maybe None Whatsoever. Forrester Research, Inc., September 282007.

[16] The Atlantic Systems Guild. Volere - Requirements Tools Listing. Www. volere.co.uk/tools.htm.

[17] B. Tvete. Introducing Efficient Requirements Management. In Proceedings International Workshop on Database and Expert Systems Applications, Los Alamitos, CA, USA, 1999. IEEE Computer Society.

[18] K. Wiegers. Automating Requirements Management. Software Development, 7(7), July 1999. 